\title{
Gruma. Un análisis microeconómico
}

Gruma.A Microeconomic Analysis

\section{Gustavo Vargas Sánchez Luis Pérez Osnaya ${ }^{* *}$}

\section{Resumen}

El estudio de la empresa Gruma es relevante desde la perspectiva del análisis microeconómico dinámico y en particular de la teoría microeconómica de la oferta. El estudio de este caso nos permite constatar algunas de las tesis de la microeconómica dinámica que subraya ciertas características de las empresas capitalistas, por ejemplo el desempeño de la empresa en su mercado, en su industria, su competitividad, su poder para fijar precios, desarrollar y gestionar las inversiones y la tecnología, así como su comportamiento en el largo plazo, el cual se caracteriza por su proceso de crecimiento, expansión y dominancia. En su dinámica de corto y largo plazo algunas de sus estrategias más destacadas son su política de fusiones y adquisiciones, de diferenciación de productos, de innovación en mercados y productos. A lo largo del ensayo subrayamos algunos de los conceptos de la microeconomía en el análisis del caso mencionado, y ofrecemos algunas hipótesis que explican el desempeño tanto en el largo como en el corto plazo de esta empresa.

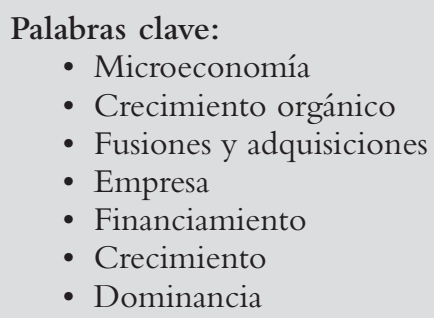

\begin{abstract}
\end{abstract}
The study of the company Gruma is relevant from the perspective of the microeconomic dynamic analysis and especially of the microeconomic theory of the offer. The study of this case allows us to state some of the theses of the microeconomic dynamics that underlines certain characteristics of the capitalist companies, for example the performance of the company on his market, in his industry, his competitiveness, his power to fix prices, to develop and to manage the investments and the technology, as well as his behavior in the long term, which is characterized by his process of growth, expansion and dominancia. In his dynamics of short and long term some of his more out-standing strategies are his politics of mergers and acquisitions, of differentiation of products, of innovation on markets and products. Along the test we underline some of the concepts of the microeconomy in the analysis of the mentioned case, and offer some hypotheses that explain the performance both in the length and in a short period of this company.

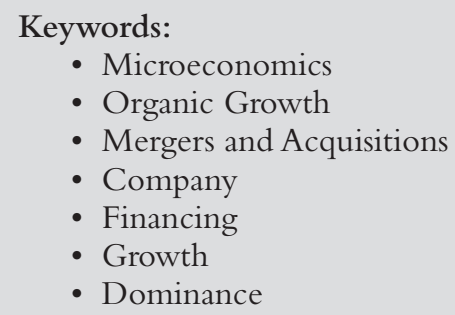

JEL: D1, D13, D21

\section{Definición, origen y fundación de la empresa}

Grupo Maseca (Gruma) es una empresa dedicada a la producción, venta, comercialización y distribución de harina de maíz y de trigo, tortillas de maíz y trigo y sus derivados de maíz a nivel nacional y mundial, actualmente es la empresa líder de este ramo en México y una de las más grandes en el mundo. Esta corporación se define a sí misma como "una empresa de alimentos, líder

* Profesor de la Facultad de Economía de la unAm. 
en la producción de harina de maíz y tortillas a nivel mundial. Gruma, S.A.B. de C.V., es la empresa de alimentos más globalizada de México, líder en la producción de harina de maíz y tortillas a nivel mundial".

Origen y fundación de la empresa

La empresa está sustancialmente ligada a la alimentación y cultura de los mexicanos, la tortilla es el alimento más importante de su dieta. El maíz en general y la tortilla en particular es un alimento que forma parte de la cultura y la idiosincrasia de los mexicanos y más ampliamente de los pueblos mesoamericanos, su consumo se remonta a la época prehispánica. La forma tradicional de elaboración de la tortilla de maíz es utilizando un método por el cual se realiza la cocción del maíz para despojarlo de su cascara, a este proceso se le conoce como nixtamalización, cuyo resultado es la "masa". El siguiente paso en la cadena de valor es la elaboración de productos derivados de la nixtamalización del maíz, entre los que destaca la tortilla.

El proceso para la elaboración de la tortilla se enfrentaba a una limitación en su producción y consumo, el cual consistía en que la masa que resulta de la nixtamalización se hacía agria y se descomponía rápidamente lo cual requería la elaboración inmediata de sus productos derivados, no más de 8 horas después de la nixtamalización. En este punto fue donde la innovación al desarrollar el proceso de harinización daría lugar a la posibilidad de conservar la masa en forma de harina evitando la descomposición de la masa. Con el proceso de harinización se puede tener una masa para la elaboración de tortillas en cualquier momento y lugar del mundo con solo agregar agua a la harina. Esta fue el origen de la industrialización y de la misma industria harinera, y esto se convertiría en la gran innovación de Gruma y al surgimiento y desarrollo que es como corporación.

Los orígenes de Gruma se remontan hacia finales de los años cuarenta del siglo xx en la localidad de Cerralvo, en el Estado de Nuevo León, México. En sus inicios se denominó como Molinos Azteca la cual contaba con una sola marca: Masa CK®. La empresa fue fundada por Roberto González Barrera y su padre Roberto González Gutiérrez. Para la instalación del primer molino, padre e hijo realizan una inversión de $\$ 75000.00^{2}$ pesos de aquellos tiempos.

El origen de la idea de elaborar harina de maíz, no fue una innovación que surgiera de la empresa, la harinización de la masa era una práctica que se

${ }^{1}$ http://www.gruma.com

${ }^{2}$ Datos obtenidos de su página de internet http://www.gruma.com 
encontraba en la cultura del norte de México, en los grupos de trabajadores migrantes que se desplazaban a los Estados Unidos a trabajar como braceros. El método de la fabricación de la harina de maíz fue conocida y tomada por los González en una de sus visitas a la ciudad de Reynosa, Tamaulipas donde comercializaban productos de abarrotes, su acierto consistió en haber tenido la visión del potencial que significaba ese proceso de producción, el cual posteriormente estandarizo e industrializó.

Si bien la producción en grandes volúmenes de la harina de maíz se podría estandarizar, esto no implicaba de su adopción inmediata en la dieta del mexicano, la empresa ha tenido que llevar a cabo una estrategia para cambiar el consumo de las familias mexicanas a favor de su nuevo producto: La harina. Sus estrategias en este sentido han cambiado con el tiempo, fue introducida primero en el mercado estatal, y después en el mercado nacional, esto último ha requerido mucho tiempo y aún no se ha generalizado.

La expansión de la empresa, como procesadora de harina de maíz, se explica por la existencia de una demanda considerable de las familias, al aumento de la población y su consumo, a las estrategias de la empresa para penetrar el mercado cambiando los patrones de consumo de la población, que ha ido aceptando muy lentamente la tortilla con base en la harina en sustitución de la tortilla elaborada con los métodos tradicionales. Otro elemento que favorece el consumo de la tortilla con base a la harina de maíz es la dinámica de la vida contemporánea a favor de la comida rápida.

Después de casi diez años de operaciones del primer molino de harina de maíz en Cerralvo, Nuevo León, la empresa pudo inaugurar una planta más, ésta fue ubicada en Acaponeta, Nayarit en 1957. De acuerdo a informes de la empresa, ésta se localizó en dicha región debido a la cercanía que había entre la planta y los campos de cultivo de maíz que en ese momento era una de las zonas de mayor producción en México. ${ }^{3}$

La distribución del producto en primera instancia fue a través de ventas al menudeo a través de pequeños comercios de abarrotes. Solo después de cierto tiempo y de las estrategias de comercialización de la empresa es que la harina de maíz se ha logrado comercializar tanto en los pequeños como en los grandes centros comerciales.

3 http://acaponeta.nayarit.gob.mx/MEDIOFISICO.pdf 


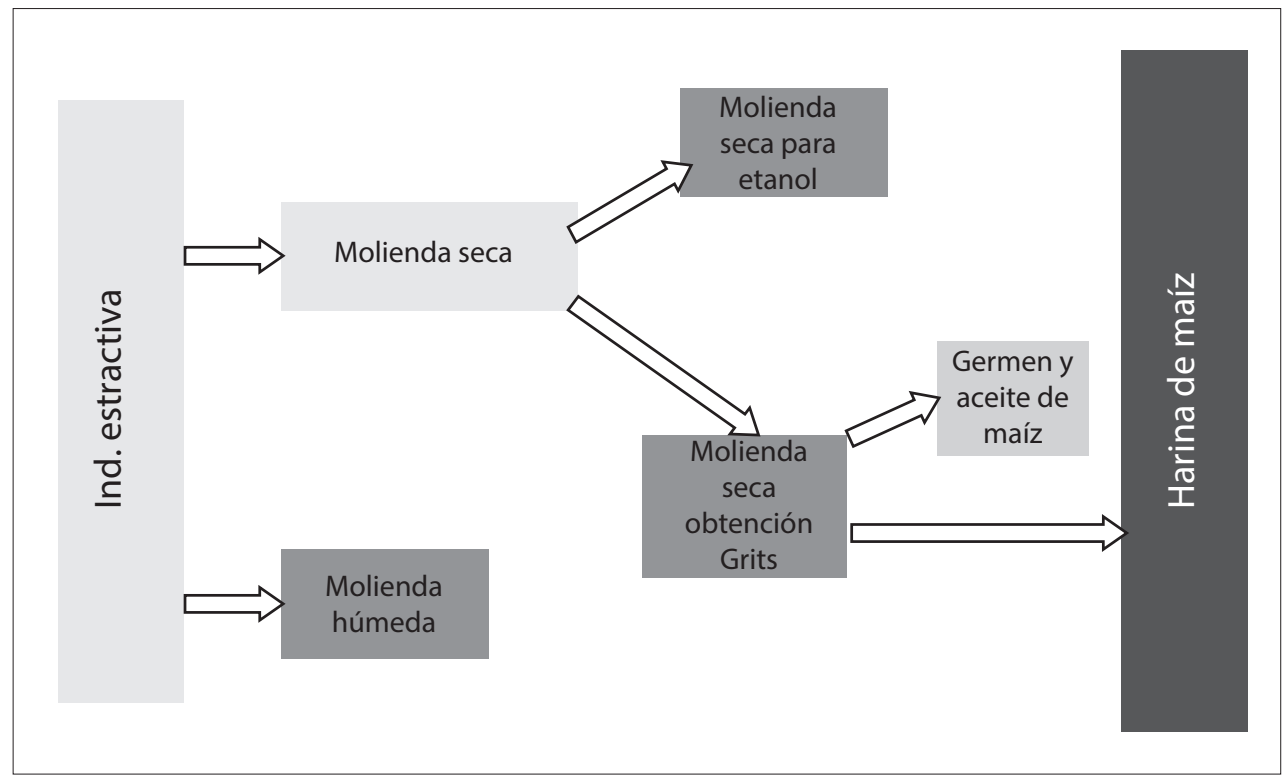

Fuente: elaboración propia

El entorno económico social y político no solo es el telón de fondo del surgimiento y desarrollo de Gruma, es también un factor determinante que explica su crecimiento. Una vez acabado el conflicto revolucionario en México, las transformaciones sociales y económicas que se dan en el país, tienen como resultado un dinamismo en los sectores industriales y agrarios, en mayor medida el industrial. Entre los años veinte y los años cuarenta aunque gran parte de los sectores económicos estuvieron estancados, otros como el textil y el de alimentos crecen manteniéndose en recuperación. ${ }^{4}$ Durante los cincuenta, los sesenta y los setenta, el espíritu nacionalista de la sociedad se vio reforzado por la política económica del modelo de sustitución de importaciones, el cual se expresó en un crecimiento acelerado de la economía, de los ingresos reales de los mexicanos y del tamaño de las familias. Todos estos factores explican el dinamismo de la demanda agregada y de la tasa de crecimiento de los mercados locales.

En ese periodo surgen varios grupos empresariales, muchos existentes y dominantes hasta nuestros días, en donde el factor común era el nacionalismo mexicano enfatizado por el partido gobernante. Los grupos empresariales se desarrollaron y consolidaron, en particular los regiomontanos crecieron y se consolidaron formando empresas y conglomerados de capital mexicano. En este contexto, para finales de los años cuarenta, en medio del crecimiento

4 Jorge Basave, Un siglo de grupos empresariales en México, textos breves de economía, p. 38. 
que se daba en el país por las inversiones en infraestructura por parte del Estado, la creciente industria, el aumento de ciudades y la creciente economía de posguerra de Estados Unidos, surge Grupo Maseca.

Las relaciones institucionales y con los gobiernos de México también son un factor que explica su crecimiento. Grupo Maseca (Gruma) a través de los años ha tenido una estrecha relación con diferentes instituciones del gobierno, por estar dentro del sector de alimentos y básicamente de la harina de maíz para la producción de tortillas, (como un alimento básico) ha estado inmerso y se ha beneficiado de muchos programas de desarrollo social enfocados a la alimentación de la población. Las políticas de precios de los diferentes gobiernos le han favorecido dando estabilidad al precio y a su producción. En 1990 se emprende la desregularización y liberación paulatina del mercado de la masa y la tortilla. Algunas investigaciones destacan el papel de las relaciones gubernamentales y de la política alimenticia en el crecimiento de la empresa, en particular se subraya políticas gubernamentales y los subsidios que mantenían precios bajos ${ }^{5}$ durante varias décadas.

Desde sus inicios en Gruma hubo una relación con políticos tanto neoleoneses como del país, así mismo se mantuvieron relaciones claves con secretarias de estado y diferentes gubernaturas. Desde sus inicios la empresa tuvo el soporte financiero del ex gobernador de Nuevo León, Bonifacio Salinas, al final de su vida este personaje termino vendiendo sus acciones a los González Barrera.

\section{Crecimiento de largo plazo de la empresa, línea del tiempo y caracterización}

Estrategias y factores que explican el crecimiento de Gruma en el LP

Línea del tiempo

En esta línea del tiempo se presentan los datos más sobresalientes de Gruma:

5 Gerardo Torres y Marcel Morales, Maíz-tortilla. Políticas y alternativas, Centro de Investigaciones Interdisciplinarias en Ciencias y Humanidades y Programa Universitario de Alimentos, UNAM, México, 1997, y C. Garrido, op. cit. 
Economía Informa núm. 386 mayo - junio • 2014

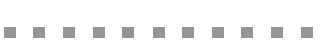

\section{Cuadro 2}

Año

1949

1957 Se abre una planta en Acaponeta, Nayarit.

1973 A petición del Gobierno de Costa Rica, Gruma incursiona en ese mercado.

1977 Adquiere la Planta de Mission Foods en Estados Unidos

1978

1982 Se instala en Texas, Estados Unidos el primer molino de maíz

1987 Inicia operaciones en Honduras

1992 Gruma adquiere el 10\% de Grupo Financiero Banorte

1993 Inicia operaciones en Guatemala,Venezuela y El Salvador

1994 Se realiza la oferta pública de Gruma en la BMV con la clave de pizarra GrumaB

1994 Inicia la distribución de tortillas de maíz y trigo en México

1996 Adquiere dos molinos de harina de maíz en Estados Unidos.

1996 Adquiere dos molinos de trigo en México.

1996 Abre en Guápiles, Costa Rica la empresa de Palmito más grande de Latinoamérica.

1997 Abre sus primeras oficinas en Londres, Inglaterra.

1998

1999

1999

2000

2004

2004

2006

2006

2006

2006

2006
Las acciones de Gruma cotizan en el New York Stock Exchange NYSE con la clave GMK

Adquiere dos molinos de trigo en México, el de GRUPO SALCIDO e INDUSTRIAL HARINERA LA ASUNCIÓN

Adquiere la empresa Molinos Nacionales C.A. MONACA de Venezuela, segundo productor de harina de trigo y maíz.

Abre su primera planta de tortillas en Europa en Inglaterra, Construcción de planta.

Adquiere un molino de maíz en Italia

Adquiere una planta de tortillas en Holanda

Adquiere la Empresa productora de Tortillas ROSITA INVESTMENTS PTY LTD de Australia

Concluye la adquisición de OZ-MEX FOODS PTY LTD con sede en Melbourne, Australia

\section{Se crea Gruma INTERNATIONAL FOODS SL en España}

Inaugura su planta número 89 en el mundo y la número 1 en Asia, en Shanghái, China

Adquiere Pride Valley Foods 
2007 Inicia operaciones la planta de Malasia, produce principalmente Tortilla Wrap, base para pizza, Naan Bread, Foldover bread.

2008 Lanza en Estados Unidos con la marca Mission la línea Life Balance dirigida a consumidores que cuidan su salud, al mismo tiempo lanza una marca de bajo precio

2008 OZ-MEX y Taco Shells se fusionan.

2009 Mission es lanzada en Australia con variedad de productos

2010 Se lanza la línea Mission Flatbreads of the world en Australia y Europa

2010 Se inaugura en Estados Unidos una planta con altos estándares de sustentabilidad, ahorro de energía y agua.

2010 Adquiere una planta en Ucrania.

2011 Adquiere una planta en Turquía (Semolina), siendo la principal en molienda de maíz y la de mejor tecnología.

2011 Adquiere Solntse en Rusia.

2011 Adquiere en Estados Unidos Casa de Oro Foods.

2012 En agosto muere Roberto González Barrera fundador de Gruma.

2012 El Lic. Juan González Moreno es nombrado presidente del consejo de administración.

2012 Se concreta la compra de acciones de ADM.

2014 Adquiere Mexfood en Europa

2015 Operará una nueva Planta en Rusia para comenzar a operar a finales de 2015

Fuente: datos obtenidos en el sitio web de Gruma con añadidos propios.

Las estrategias competitivas y de crecimiento de la empresa han cambiado en el tiempo y se han ido orientando hacia su internacionalización. Este último proceso comenzó en 1973 cuando por petición del gobierno de Costa Rica lleva sus productos a ese país. Si bien lo anterior es cierto, no es sino hasta finales de la década de los ochenta y de forma clara en los noventa, que como resultado de la apertura de la economía a los tratados comerciales (El gatT y el TLC) que esta y otras empresas inician una clara expansión a los mercados internacionales.

De acuerdo a la línea de tiempo antes presentada, las estrategias de la empresa en su proceso de crecimiento han sido de diferente tipo, entre ellas que destacan: La innovación de producto, el desarrollo de procesos, la integración vertical y horizontal, la diferenciación de producto, la entrada a nuevos mercados, tanto nacionales como internacionales. Destacan sus desarrollos tecnológicos y administrativos. 
La estrategia de financiamiento para el crecimiento tiene un rol muy importante en la expansión de la empresa, en este sentido destaca en 1992 la adquisición de 10\% del grupo financiero Banorte y dos años después su entrada a la BMV, y posterior mente a la bolsa de NY. Estas estrategias permitieron que la empresa contara con flujos de financiamiento para realizar sus planes de expansión que se acelerarán en los años noventa y la primera década del presente siglo hacia el resto del mundo. El papel del financiamiento para el crecimiento muestra claramente su efecto en que esta empresa creció mucho más aceleradamente en los últimos 20 años después de la adquisición que realizó del Grupo Financiero Banorte en 1992 que en los años anteriores. La aplicación de estas estrategias han resultado en que hoy día Gruma es la empresa global de alimentos mexicana líder en la producción de harina de maíz y tortilla a nivel mundial, así como un importante jugador en harina de trigo y alimentos básicos, con marcas líderes en la mayoría de sus mercados, por lo que cuenta con 100 plantas y presencia en más de 100 países, con más de 20 mil empleados. ${ }^{6}$

En términos del análisis microeconómico podemos añadir que la trayectoria de este empresa expresada en su línea del tiempo muestra que hasta el momento no ha encontrado algún límite en su crecimiento, aún en lo que se refiere a los gastos de organización que puedan resultar de una empresa cada vez más grande. La evidencia empírica muestra que no parece existir una curva de costos medios y marginales de largo plazo en forma de U como afirma la teoría tradicional. El desarrollo histórico de Gruma ha llevado a esta empresa a convertirse en una gran corporación la cual tiene presencia en todo México y en el mercado internacional.

\section{Gruma como Megacorporación transnacional}

Gruma Corporation cuenta con 29 plantas de producción de harina de maíz y productos como la tortilla en Estados Unidos y 8 en Europa entre las que destaca 1 de panes planos, 3 de harina de maíz y grits y 4 plantas de tortilla y productos relacionados contando entre sus marcas principales a Maseca, Mission y Guerrero.

En México su principal subsidiaria es Grupo Industrial Maseca (GIMSA) dedicada principalmente a la producción de harina de maíz la cual cuenta con 18 plantas para la elaboración de este producto, así como 1 planta de harina de trigo y una más para otros productos. También cuenta con otras subsidiarias como Molinera de México que produce harina de trigo, cuenta con 9 plantas 6 http://www.gruma.com/vEsp/Acerca/acerca_esto.asp 
y su marca principal es Selecta. Así mismo cuenta con Productora y Distribuidora Azteca S.A. (PRODISA) que produce tortilla de maíz, tortilla de trigo y otros productos relacionados, cuenta con 2 plantas y su marca principal es Mission (véase cuadro 3)

Gruma Centro América dedicada principalmente a la producción de harina de maíz, snacks, tortillas, arroz y palmito, cuenta con 12 plantas distribuidas en Centro América, sus marcas principales son Maseca, Tosty, tortiricas y Mission. Gruma incursiona en Costa Rica en 1972, lo que le permitió exportar sus productos y enfrentar a nuevos mercados.

Gruma Venezuela cuenta con 15 plantas para la elaboración de harina de maíz, harina de trigo, avena, arroz, condimentos y pasta, sus principales marcas son Robin Hood y Juana.

Gruma Asia y Oceanía cuenta con 3 plantas y se dedica principalmente a la elaboración de tortilla de maíz y de trigo, panes planos y otros productos, su marca principal es Mission. El control total de estas plantas lo tiene Gruma International Foods, S.L., quien además controla Pride Valley Foods en Inglaterra. 
Economía Informa núm. 386 mayo - junio • 2014

\begin{tabular}{|c|c|c|c|c|}
\hline \multicolumn{5}{|c|}{$\begin{array}{l}\text { Cuadro 3: } \\
\text { Presencia de Gruma por región geográfica. }\end{array}$} \\
\hline País & Produce & Marcas & \multicolumn{2}{|c|}{ Plantas } \\
\hline $\begin{array}{l}\text { Estados Unidos } \\
\text { y Europa }\end{array}$ & $\begin{array}{l}\text { Gruma } \\
\text { Corporation, } \\
\text { es productor de harina de } \\
\text { maíz, tortilla de maíz, tortilla } \\
\text { de trigo, panes planos y otros. }\end{array}$ & $\begin{array}{l}\text { Maseca, } \\
\text { Mission y } \\
\text { Guerrero }\end{array}$ & $\begin{array}{l}\text { Estados } \\
\text { Unidos } \\
\text { *23 plantas } \\
\text { de Tortilla } \\
\text { y productos } \\
\text { relacionados. } \\
\text { *6 de Harina } \\
\text { de Maíz. }\end{array}$ & $\begin{array}{l}\text { Europa } \\
\text { *4 plantas } \\
\text { de tortilla y } \\
\text { productos } \\
\text { relacionados. } \\
\text { *1 de panes } \\
\text { planos. } \\
\text { *3 de Harina } \\
\text { de maíz y } \\
\text { Grits. }\end{array}$ \\
\hline \multirow{4}{*}{ México } & $\begin{array}{l}\text { GIMSA, productora de harina } \\
\text { de maíz }\end{array}$ & Maseca & $\begin{array}{l}\text { *18 de Harina } \\
\text { de maíz. } \\
\text { *1 de harina } \\
\text { de trigo. } \\
\text { *1 de otros } \\
\text { productos. }\end{array}$ & \\
\hline & $\begin{array}{l}\text { Molinera de México. Pro- } \\
\text { ductora de harina de trigo }\end{array}$ & Selecta & ${ }^{*} 9$ plantas & \\
\hline & $\begin{array}{l}\text { PRODISA. Productor de tortilla } \\
\text { de maíz, tortilla de trigo y } \\
\text { productos relacionados }\end{array}$ & Mission & *2 plantas & \\
\hline & $\begin{array}{l}\text { INTASA. (Tecnomaíz) In- } \\
\text { vestigación y tecnología } \\
\text { de Gruma. Investigación y } \\
\text { desarrollo. Ingeniería diseño } \\
\text { y construcción de plantas. } \\
\text { Venta de maquinaria en vo- } \\
\text { lúmenes pequeños. Capacita- } \\
\text { ción a empleados. }\end{array}$ & $\begin{array}{l}\text { Rodotec, } \\
\text { Electra y } \\
\text { Tortec y } \\
\text { Batitec }\end{array}$ & ${ }^{*} 2$ plantas & \\
\hline Venezuela & $\begin{array}{l}\text { Gruma Venezuela. Productor } \\
\text { de harina de maíz, harina de } \\
\text { trigo. Avena, arroz, condi- } \\
\text { mentos y pasta. }\end{array}$ & $\begin{array}{l}\text { Robin } \\
\text { Hood y } \\
\text { Juana }\end{array}$ & $\begin{array}{l}\text { *5 de harina } \\
\text { de maíz. } \\
\text { *5 de harina } \\
\text { de trigo. } \\
\text { *5 de otros } \\
\text { productos. }\end{array}$ & \\
\hline Centro America & $\begin{array}{l}\text { Gruma Centro America. } \\
\text { Harina de maíz, tortillas de } \\
\text { maíz y otros productos. }\end{array}$ & $\begin{array}{l}\text { Maseca, } \\
\text { TortiRicas, } \\
\text { Mission y } \\
\text { Tosty }\end{array}$ & *12 Plantas & \\
\hline Asia y Oceanía & $\begin{array}{l}\text { Gruma Asia y Oceania. } \\
\text { Productor de tortilla de maíz, } \\
\text { tortilla de trigo, panes planos } \\
\text { y otros productos }\end{array}$ & Mission & *3 Plantas & \\
\hline
\end{tabular}

Fuente: elaboración propia con datos de Gruma 
Estrategia de penetrar los mercados extranjeros: El ingreso a otros mercados requirió de estrategias competitivas eficaces, por ejemplo, en 1977 ingresó a Estados Unidos con la producción de tortillas empacadas y posteriormente harina de maíz y otros productos relacionados con la tortilla, en este mercado tuvo que enfrentar la competencia de multinacionales como Archer Daniels Midland (ADM), Anheuser-Busch, PepsiCo, Tyson y Conagra, entre otras. Su posterior asociación con ADM en 1996 le permitió fortalecer su presencia en el mercado de harina de trigo en México y tener mayor penetración en Estados Unidos.

En 1997 Gruma inicia un periodo acelerado de expansión en el extranjero, adquirió dos plantas de tortillas en operación en los Estados Unidos y construyó otras tres en ese país. Actualmente cuenta con plantas en Seattle, San Francisco, Los Ángeles, Phoenix, San Diego, Dallas, Oklahoma, Florida y en Rancho Cucamonga, California. En 2005 comenzó la construcción de una planta en Pennsylvania y adquirió parte de los activos de la división de comida mexicana de Cenex Havest States (tres plantas de tortillas localizadas en New Brighton, Minnesota; Railhead, Texas; Phoenix, Arizona). La mayoría de sus productos con la marca Mission son vendidos en los mercados de menudeo y de servicios alimenticios y restaurantes.

En Europa llegó con la construcción de una planta de tortillas en Coventry, Inglaterra en 2000. En 2004 realizó dos adquisiciones en Europa para fortalecer su presencia en la región: Ovis Boske, compañía de tortillas de harina de trigo con base en Holanda y 51\% de participación en Nuova De Franceschi \& Figlu, empresa con base en Italia. En septiembre de 2006 inauguró su primera planta en Asia en Shanghái, China.

Otra estrategia que necesitamos subrayar es la de focalización en un producto o línea de productos. Desde 1993 el grupo buscó reorientar sus programas de inversión y recursos administrativos a la harina de maíz y las tortillas; los negocios que no estaban relacionados directamente con esa actividad fueron vendidos. En 1995 vendió una fábrica de conservas de Centroamérica, y en México los restaurantes de hamburguesas Burger Boy. Ingresó en la elaboración de pan de caja, sin embargo decidió descontinuar esas operaciones en México, Centro América y Estados Unidos. A finales de 2001 vendió a Grupo Bimbo el negocio de pan en Centroamérica y el equipo para la manufactura de pan en México. En febrero de 2002 vendió algunos activos de las operaciones de pan en Estados Unidos. Todo esto con el fin de centrarse en la expansión de sus capacidades y mejoras tecnológicas de sus operaciones. En esa dirección se dirigieron sus acciones de agregar líneas de producción a las 
plantas existentes, como la elaboración de tortillas de trigo, cabe mencionar que $95 \%$ de sus ingresos provienen de la harina de maíz y de los dos tipos de tortillas que produce.

Para Gruma ha sido muy importante desde 1996 la alianza con Archer Daniels Midland Company “ADM", ya que esta alianza permitió a ambas compañías utilizar los canales de distribución tanto en México como en Estados Unidos, llegando a más mercados.

La estrategia general de la empresa ha sido flexible y se ha adaptado a las condiciones cambiantes de la economía. Actualmente el sistema agroalimentario mundial ha cambiado radicalmente, las empresas no operan aisladas, los grandes productores en las actividades de la agroalimentaria llevan a cabo una "integración vertical externa" centrada en formar complejos agroindustriales por medio de la operación vertical de empresas productoras de semillas, biotecnológicas, agroquímicos, agroindustriales y alimentarias, y Gruma participa directa o indirectamente en ese proceso.

\section{El crecimiento reciente de Gruma}

\section{I. (2002-2012): análisis económico y financiero}

En este apartado realizamos un análisis económico financiero de la evolución reciente de la empresa. La información económica y financiera está basada tanto en los reportes emitidos por la empresa como por datos obtenidos de la revista Expansión Las 500 empresas más grandes de México, las cifras están en pesos constantes (2003).

Ventas

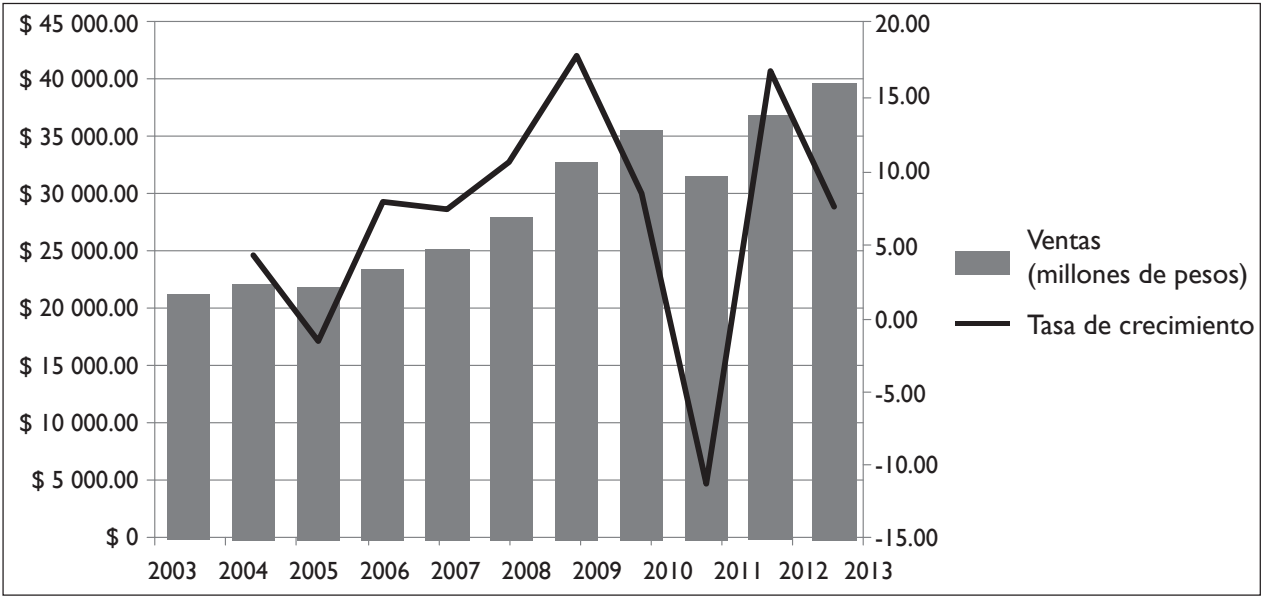


El cuadro de ventas de la empresa muestra, que de 2002 a 2012, los ingresos por este concepto fueron notables en su crecimiento. Con excepción de 2010, donde hubo una caída, explicada por la devaluación que sufrió el Bolívar en Venezuela, este mercado representaba $12 \%$ de sus ventas mundiales para el 2010. Aun con esta caída el promedio de ventas durante el periodo (20022012) fue de $\$ 28893.17$ millones de pesos. La tasa de crecimiento promedio anual es de 6.61 por ciento.

En cuanto a la utilidad de operación también reporta una tendencia creciente, su crecimiento promedio durante el periodo de estudio fue de $5.4 \%$ en el periodo (2002-2012), en los años 2005 y 2007 se reportan disminuciones que se deben a gastos de operación en Gruma Corporation y GiMsa, alzas en los precios de gasolinas, movimiento de productos entre plantas, gastos de promoción y mercadeo. Para el año 2010 la caída en este concepto es debido a problemas en Venezuela, como la devaluación de la moneda y las expropiaciones de sus plantas. La recuperación, primordialmente se debe a eficiencias en sus plantas, ahorro de combustibles y energéticos. Es decir una mejor operatividad.

En cuanto a la utilidad neta de Gruma ha ido aumentando en el periodo, sin embargo en el 2008 se reportan resultados negativos debido principalmente a que en el periodo de la crisis internacional, la empresa realizó operaciones de financiarización lo que le originó perdidas sustanciales. Gruma perdió más de $\$ 100000$ millones de dólares en productos financieros llegando a tener una utilidad neta negativa de $\$ 8650.50$, millones de pesos, estos resultados provocan el aumento de pasivos para compensar dichas pérdidas. Nótese que los resultados no se debieron a la baja en ventas, ni por el aumento de precio o baja en el volumen vendido, las pérdidas se explican por factores que no tenían que ver con la actividad principal del negocio sino a sus operaciones de financiarización.

La reducción en la utilidades en 2010 se debió en gran parte a la expropiación de sus activos en Venezuela y la devaluación del bolívar. Sin embargo, la recuperación de Gruma fue inmediata, los planes de la empresa a largo plazo generan esta recuperación.

En cuanto al activo total de Gruma durante los primeros años de la década de 2002 a 2012 muestra una tendencia creciente, sin embargo, hay ciertos ajustes a partir de 2009. De 2003 a 2008 el incremento del activo se explica por la adquisición de plantas en diferentes partes del mundo. Durante 2009 y 2010 la caída se explica a la perdida cambiaria, a la devaluación del bolívar y a la desadquisición de varios de sus negocios tanto en Centro América como 
en México y Estados Unidos. Como se mencionó la estrategia de Gruma fue eliminar varias de las líneas tanto de pan como de restaurantes, actividades que no correspondían a su negocio principal.

El activo circulante ha aumentado durante el periodo 2002 a 2012 a una tasa promedio de 9.17\%, exceptuando los años 2009-2010 cuando se registró una caída debido a los problemas en Venezuela. La tendencia ha sido a la alza, inclusive en la crisis de 2008. Sin embargo al excluir la crisis y los problemas en Venezuela, el activo circulante ha tenido una gran mejoría dentro de la empresa, debido principalmente a aumentos en sus ventas, inventarios y a la recompra de sus acciones a ADM en el 2012.

El pasivo total de Gruma se ha ubicado en niveles moderados, exceptuando el año de crisis 2008. En este año Gruma adquiere deudas debido a la perdida que tuvo en productos financieros, su deuda tanto en corto como en largo plazo aumenta en ese año. En los años siguientes su estrategia fue liquidar sus deudas lo más rápido posible. El pasivo circulante tiene un comportamiento similar a la del pasivo total.

Respecto al empleo, a pesar de las desadquisiciones y cierre de plantas temporal o definitivamente, no se disminuye la tasa de empleo manteniéndose en promedio con más de 17000 empleados durante el periodo 2002-2012 y llegando a superar los 21000 empleos en el último año.

La productividad del trabajo crece continuamente. Esta tendencia se vio afectada temporalmente por la expropiación de los activos de la empresa en Venezuela en 2010. La tasa de crecimiento de todo el periodo (2002-2012) es de $2.38 \%$. Por su parte la productividad del capital (ventas/patrimonio ${ }^{7}$ ) en el transcurso de los años 2002 a 2012 muestra una tendencia a la alza, la tasa de crecimiento promedio es de casi 18.1 por ciento.

El promedio de crecimiento de la tasa de ganancia (utilidad neta sobre patrimonio) presenta una tendencia creciente, esto es claro en el periodo 2002-2012, si eliminamos el dato de 2008, año en el cual dicha tasa presenta resultados negativos, de esta forma se reporta un tasa de crecimiento promedio positiva de $32.5 \%$ de este rubro.

Como resultado de los datos anteriores el capital por trabajador se ha reducido de forma sustancial durante el periodo de estudio (2.8\%), lo cual habla

\footnotetext{
${ }^{7}$ Conjunto de bienes, derechos y obligaciones de una persona fisica o jurídica, privada o pública. La suma de los valores de los bienes y derechos constituye el patrimonio bruto o activo total del balance. El patrimonio neto o neto patrimonial viene dado por la diferencia entre el patrimonio bruto y el valor de las deudas o pasivo exigible. El término patrimonio se utiliza en economía como sinónimo de capital, riqueza o hacienda. Propiedad real de una empresa o individuo, definida como la suma de todos los activos, menos, la suma de todos los pasivos.
} 
del crecimiento en la productividad del trabajo y del capital así como de la eficiencia en las estrategias de la empresa.

\section{Productividad del trabajo Ventas/Empleo 2002-2012}

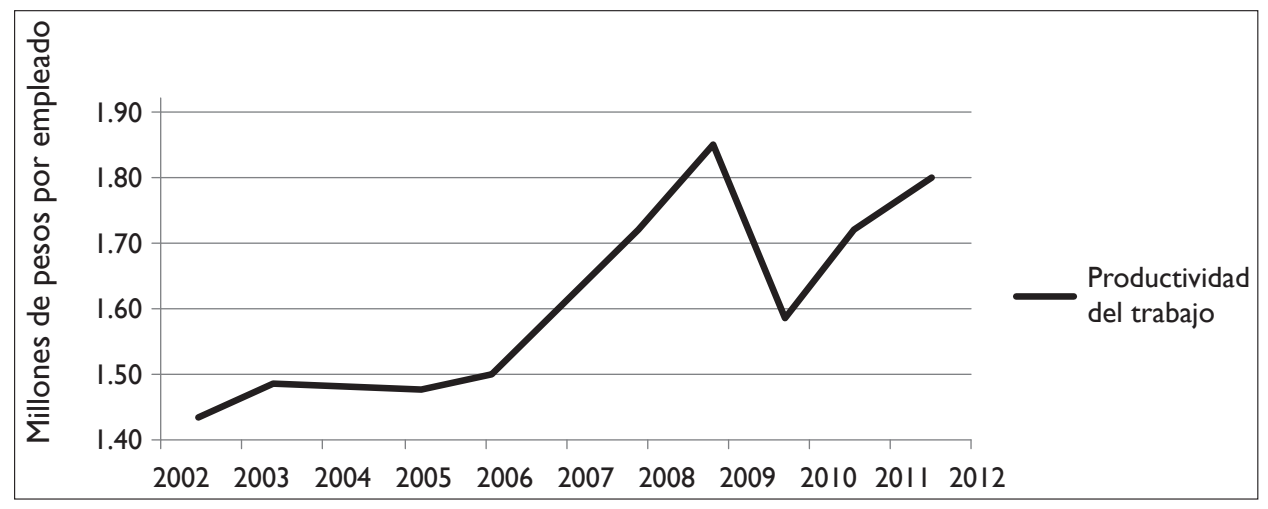

En esta trayectoria de crecimiento de largo plazo de la empresa ha sido exitosa con excepción de los años de 2008 y 2010. En el primero se ve afectada su utilidad neta, debido a la pérdida de casi mil millones de dólares en productos financieros derivados y variaciones en el tipo de cambio, lo cual afectó su rentabilidad. En 2010 la rentabilidad se vio afectada por la expropiación de Monaca en Venezuela, así como la devaluación de la moneda. A pesar de estas dificultades, la situación financiera de la empresa se ha mantenido en niveles sanos al mantener un nivel positivo de apalancamiento que en promedio fue de $30.31 \%$ en el periodo (2002-2012).

\section{Estrategias de innovación y desarrollo}

Una de las estrategias que explica el crecimiento de Gruma es la innovación y el desarrollo de sus productos y procesos, en general la empresa ha utilizado diferentes estrategias a lo largo de su historia, como por ejemplo: 1) Integración vertical y horizontal; 2) desinversiones; 3) alianzas; 4) adquisiciones; 5) se ha internacionalizado y ha llegado a otros mercados geográficos. ${ }^{8}$

${ }^{8}$ Grupos Económicos en la Industria de Alimentos. Las Estrategias de Gruma Rendón Trejo Aracely, Morales Alquicira Andrés. Documento consultado el 11 de Mayo de 2013 en http://148.206.107.15/ biblioteca_digital/estadistica.php?id_host=6\&tipo=ARTICULO\&id=4931\&archivo=1-3144931fbx.pdf\&titulo= Grupos $\% 20$ econ $\%$ C3\%B3micos $\% 20$ en $\% 201 \mathrm{a} \% 20$ industria $\% 20 \mathrm{de} \% 20$ alimentos.\%20Las\%20estrategias\%20de\%20Gruma 
Parte del éxito de Gruma, en cuanto a la investigación y desarrollo, consiste en el desarrollo de su propia tecnología pues fabrica la maquinaria con la que se elaboran las tortillas, y el desarrollo de sus productos. Aunque no ha sido muy significativo el ingreso que obtiene por la fabricación de maquinaria para la industria harinera, esta fue una manera de consolidarse en el mercado con la harina de maíz. En este sentido durante 1997 a 2001, invirtió cerca de 202 millones de pesos en el rubro de investigación y desarrollo; en 2005 destinó 40 millones de pesos. ${ }^{9}$

Gruma comenzó a operar un departamento especializado en Investigación y Desarrollo (I+D) a finales de los años sesenta, el cual al inicio solamente era parte de un área dentro de la empresa, posteriormente a principios de la década de los ochenta creó una subsidiaria especializada para el desarrollo de tecnología e investigación llamada "DITSA" (Desarrollo de Tecnología S.A.). $\mathrm{Su}$ función es investigar y a desarrollar patentes e innovaciones en procesos e ingeniería para la construcción de sus plantas. Para 1995 se crea el centro de Investigación y Tecnología Avanzada, INTASA. Este centro fue creado para el desarrollo de nuevas tecnologías e innovación de producto, equipo y procesos. Se contemplan programas de asimilación, transferencia de tecnología y comercialización. Estos centros se encuentran al norte de México.

INTASA, tiene dos subsidiarias: Tecnomaíz S.A. y Constructora Industrial Agropecuaria S.A. de C.V. (CIASA) cuya actividad principal es la investigación y desarrollo en equipo y servicios de construcción para Gruma y provee de equipo a terceros. La investigación y desarrollo en tecnología para la molienda de maíz y producción de tortilla así como la ingeniería, diseño de planta y construcción la lleva a cabo mediante INTASA y CIASA, las que además de administrar y supervisar el diseño y la construcción de nuevas plantas, proporcionan servicios de consultoría y entrenamiento para la producción de tortillas. Algunos de los equipos y maquinaria creada por la división de desarrollo y tecnología se han utilizado en el mercado de los de tortillas en Estados Unidos. En tanto las primeras máquinas producían hasta 600 tortillas por minuto, hoy día producen 2000 tortillas por minuto.

Tecnológicamente Gruma ha desarrollado desde maquinas tortilleras, hasta programas para reducir el consumo de agua y combustibles en la elaboración de sus productos, pasando por innovaciones en sus productos, como líneas saludables (fitness), líneas con vitaminas y fortificadas.

${ }^{9}$ Datos obtenidos de sus reportes anuales. 
Algunas de las actividades de investigación y desarrollo se han orientado a:

- Aumentar la eficiencia de su tecnología en la producción de harina de maíz y de trigo.

- Mantener alta calidad en los productos.

- Desarrollar productos y equipos de manufactura nuevos y mejorados.

- Incrementar el tiempo de vida en anaquel de productos de harina y maíz.

- Mejorar y expandir el sistema de tecnología de la información.

- Ingeniería, diseño industrial y construcción de plantas.

- Cumplimiento de la regulación ambiental.

El desarrollo de nuevos productos que entiendan mejor las necesidades de los consumidores y que satisfagan los gustos regionales.

La generación de nuevos canales de distribución.

La creación de nuevas estrategias de negocios.

La inversión en investigación de nuevas tecnologías sustentables que resulten no sólo más eficientes y productivas, sino amigables con el medio ambiente. El uso de estrategias mercadológicas creativas basadas en el entendimiento del comportamiento del consumidor

La creación de eficiencia en las operaciones.

Los conocimientos, procesos y productos elaborados por este grupo han sido protegidos mediante el registro de patentes en Estados Unidos en este sentido de 1968 a 2006 el grupo había registrado 54 patentes.

Las acciones de las grandes empresas o grupos en México se inscriben dentro de la dinámica de competencia de las empresas trasnacionales de la industria de alimentos y bebidas. Las empresas del país, tal como lo hacen las grandes empresas extranjeras en la actividad alimentaría y de bebidas, buscan ampliar sus líneas de productos y diversificar sus mercados geográficos.

Si bien la empresa ha invertido en innovación y desarrollo, el proceso que la empresa utiliza para la elaboración de harinas así como de tortillas no ha variado mucho al método que utilizaban desde sus inicios como procesos de industrialización. Esta, la industrialización es lo que le permitió a Gruma hacer su primera innovación, pasando a través de los años a procesos cada vez más tecnificados. Estas innovaciones se presentan principalmente en productos diversificados, nuevos mercados, eficacia en sus plantas así como en mejora de procesos al elaborar la harina y en desarrollo tecnológico para producir más con menores costos. En el cuadro siguiente se presenta las innovaciones más destacadas de la empresa, siguiendo la clasificación clásica de J. Schumpeter. 
Economía Informa núm. 386 mayo - junio • 2014

Clasificación de innovaciones de la empresa Gruma

\begin{tabular}{|c|c|c|c|c|c|}
\hline Organización & Proceso & Producto & Insumo & Mercado & Otros \\
\hline $\begin{array}{l}\text { Eficientes } \\
\text { procesos de } \\
\text { Admón. y } \\
\text { operación, } \\
\text { soporta- } \\
\text { dos por las } \\
\text { TIC's; Se les } \\
\text { comunica a } \\
\text { los empleados } \\
\text { de todos los } \\
\text { niveles la or- } \\
\text { ganización de } \\
\text { los procesos } \\
\text { claves de la } \\
\text { compañía en } \\
\text { el largo plazo } \\
\text { así como sus } \\
\text { objetivos. } \\
\text { Equipos en } \\
\text { acción: equi- } \\
\text { pos multidis- } \\
\text { ciplinarios, } \\
\text { para resolver } \\
\text { problemas } \\
\text { mediante el } \\
\text { análisis en } \\
\text { situaciones } \\
\text { concretas. }\end{array}$ & $\begin{array}{l}\text { Maquinas que } \\
\text { producen hasta } \\
1200 \text { tortillas } \\
\text { por minuto y } \\
400 \text { de harina; } \\
\text { desarrollo } \\
\text { un sistema } \\
\text { patentado que } \\
\text { disminuye hasta } \\
\text { en } 81 \% \text { el uso } \\
\text { de agua potable } \\
\text { en la nixtamali- } \\
\text { zaciòn del maíz } \\
\text { tratando así de } \\
\text { homogenizarlo } \\
\text { en todas sus } \\
\text { plantas. Reduce } \\
\text { el consumo de } \\
\text { gas en } 12 \% \text { con } \\
\text { un recuperador } \\
\text { de calor en } \\
\text { producción de } \\
\text { tortilla y toto- } \\
\text { pos así como el } \\
\text { ahorro de } 55 \% \\
\text { de gas en cocer } \\
\text { el maíz. }\end{array}$ & $\begin{array}{l}\text { En Estados Unidos se } \\
\text { le consideraba como } \\
\text { Commodity. Servicio } \\
\text { al cliente y productos } \\
\text { de alta calidad aumento } \\
\text { el consumo de tortilla } \\
\text { en todos los sectores } \\
\text { de la población; Harina } \\
\text { de Maíz con micro- } \\
\text { nutrientes y proteína } \\
\text { de soya aumenta valor } \\
\text { nutricional; HM libre } \\
\text { de organismos genéti- } \\
\text { camente modificados le } \\
\text { permite competir en el } \\
\text { mercado Europeo gene- } \\
\text { rándole un crecimiento } \\
\text { de hasta 250\% de 1998 } \\
\text { a 1999; MASECA } \\
\text { Premium plus yVITAL; } \\
\text { Masa Mixta Organic. } \\
\text { Grits que se deriva de la } \\
\text { molienda de maíz y que } \\
\text { sirve para la elaboración } \\
\text { de cerveza, cereales y } \\
\text { snacks. }\end{array}$ & $\begin{array}{l}\text { Opciones } \\
\text { de empa- } \\
\text { que que } \\
\text { permiten } \\
\text { controlar } \\
\text { los costos } \\
\text { y mante- } \\
\text { ner precios } \\
\text { mode- } \\
\text { rados; } \\
\text { Empaques } \\
\text { con temas } \\
\text { alusivos a } \\
\text { la época o } \\
\text { como ayu- } \\
\text { da médica } \\
\text { como la } \\
\text { auto-ex- } \\
\text { ploración } \\
\text { mamaria } \\
\text { para evitar } \\
\text { cáncer de } \\
\text { mama. }\end{array}$ & $\begin{array}{l}\text { Adquisiciones } \\
\text { en mercados a } \\
\text { nivel mundial. } \\
\text { Implementa- } \\
\text { ción de cinco } \\
\text { ejes dentro de } \\
\text { sus mercados: } \\
\text { Salud, bienestar, } \\
\text { placer, conve- } \\
\text { niencia y ética. } \\
\text { Nuevos mé- } \\
\text { todos merca- } \\
\text { dológicos para } \\
\text { educar a los } \\
\text { consumidores a } \\
\text { comer tortilla. } \\
\text { Uso de Redes } \\
\text { sociales como } \\
\text { Facebook y } \\
\text { canales de vi- } \\
\text { deo en Youtube } \\
\text { en Europa, } \\
\text { donde se dan a } \\
\text { conocer rece- } \\
\text { tas, noticias y } \\
\text { promociones. }\end{array}$ & $\begin{array}{l}\text { Adquisi- } \\
\text { ción de } \\
\text { GFBanorte }\end{array}$ \\
\hline
\end{tabular}

Fuente: elaboración propia.

En los procesos de innovación en los últimos años la llamada revolución verde hace que las empresas a nivel mundial pongan atención en el medio ambiente, Gruma no es la excepción, la empresa ha tenido un acercamiento a tecnologías verdes, lo que en un principio fue solo una reducción de costos en procesos, se convierte en innovaciones ambientales. Ejemplo de esto es que Gruma ha incorporado a algunas de sus plantas eficiencias de combustibles y ahorro de agua en sus procesos, uso de energías renovables y alta tecnología. En sus reportes la empresa hace alusión a este tipo de mejoras. 


\section{Conclusiones}

La gran innovación de Gruma fue la producción e industrialización de la harina de maíz, si bien este fue un invento de cultura de los migrantes, pero como lo ha afirmado J. Schumpeter, lo que genera el desenvolvimiento económico y las ventajas para las empresas no son los inventos, sino que estos se convierten en innovaciones en el sentido económico: esto es que transformen los modos de producción anteriores.

La estrategia de crecimiento de la empresa Gruma ha consistido en un crecimiento orgánico invirtiendo en nuevas plantas, en tecnología e innovación, diferenciación de su producto, y explorando nuevos mercados. Su segunda estrategia ha consistido en F\&A en especial se ha orientado hacia las adquisiciones. Su expansión la ha realizado a través de la compra de otras empresas ya existentes en México y en el extranjero.

El crecimiento de la empresa se ha dado en una primera etapa en el mercado interno, expandiéndose a lo largo del territorio nacional, y en el periodo más reciente con la apertura comercial en el mercado internacional, destaca su crecimiento en los Estados Unidos, si bien recientemente ha continuado su expansión hacia Europa, Rusia y China.

Dos factores destacan en su estrategia de crecimiento, en primer lugar la diferenciación de su producto. Y en segundo lugar, y de forma muy especial sus nuevas estrategias de financiamiento, las cuales se pueden dividir en dos: el financiamiento a través de "su propio banco" lo cual logra a través de su participación accionaria en BANORTE y la segunda forma de financiamiento a través de los mercado de valores, en este sentido destacó su ingreso a la BMV y al New York Stock Exchange. Es necesario decir que la empresa moderna en su objetivo de expansión no está necesariamente limitada a la generación de su propio flujo de efectivo. El financiamiento externo se convierte en una poderosa palanca de crecimiento.

Modificación en los patrones de consumo. La expansión de esta empresa y de esta industria no solo implicó la transformación de las formas de producción sino también el cambio en los patrones de consumo de la población mexicana. Esta transformación ha sido lenta sobre todo porque la cultura de los consumidores sigue siendo a favor de las formas tradicionales de producción, y el consumo de las tortillas a partir de la harina es un cambio a la idiosincrasia de los mexicanos.

Finalmente, cuando hacemos análisis de las empresas, que la característica más importante de ellas no es la búsqueda de un punto de equilibrio estable, o 
incluso dinámico, sino que de acuerdo a su naturaleza, lo que persiguen es un crecimiento, concentración, y dominancia mayor de su mercado. Este proceso no es lineal y constante se encuentra con muchos obstáculos como los que Gruma encontró en Venezuela. A pesar de esos ensayos fallidos su estrategia de largo plazo ha sido exitosa, por lo cual ha logrado el crecimiento ahora en el ámbito internacional.

\section{Bibliografia}

Barber, Carlos. Moreno, Raúl, Casos empresariales Tomo II. Universidad Anáhuac del Sur. 2005.

Domínguez, Lilia. Brown, Flor, Estructuras de Mercado de la Industria mexicana. Un enfoque teórico y empírico, Facultad de Economía. unam. 2003.

Domínguez, Lilia. Brown, Flor, Organización Industrial. Teoría y aplicaciones al caso mexicano, Facultad de Economía. Unam. 2012.

Flores, José. Tirado Ramón, Compiladores. Economía Industrial y agrícola en México ante la apertura, UAM, 2001.

I. Casar, José; Márquez, Carlos; Marván, Susana; Ros, Jaime, La organización Industrial en México, Siglo Veintiuno editores, México, 1990.

Marichal, Carlos; Cerutti, Mario (comp.), Historia de las grandes empresas en México, 1850-1930, Universidad Autónoma de Nuevo León, FCE, México, 1997.

Mascareñas, Juan, Fusiones y adquisiciones de empresas, McGraw-Hill, 2005.

Shumpeter, Joseph, Ciclos económicos: análisis teórico, histórico y estadístico del proceso capitalista, McGraw-Hill, 1964

Sylos-Labini, Paolo, Oligopoly and Technical Progress, Literary Licensing, LCC. 2011.

Vargas, Gustavo, Introducción a la Teoría económica. Un enfoque latinoamericano. Pearson Education, México, 2006.

\section{Fuentes}

http://www.diariocultura.mx/2012/05/molino-el-hercules/

Historia Molinos Hercules

http://www.cnmaiz.org.mx Camara Nacional De Maiz Indsutrializado

Http://www.gimsa.com/htmle/infohtml/HISTORIA.htm

Capacidad De Produccion

http://www.poder360.com/article_detail.php?id_article=5201

Relaciones Politicas Con Gruma

http://www.dineroenimagen.com/2012-08-27/5449 Bonifacio Salinas Leal 